\title{
FEATURE
}

\section{Managing crop nutrients to achieve water quality goals}

\author{
Andrew Sharpley, Matthew J. Helmers, Peter Kleinman, Kevin King, April Leytem, and Nathan Nelson
}

$\mathbf{M}$

anaging agricultural nutrients to achieve water quality goals involves complexities best organized around source and transport processes, as captured in site assessment tools used for nutrient management decision support. Source is governed by nutrient use efficiency (NUE) by crops and land management, while transport is governed by landscape and hydrologic controls. These concepts are useful for strategic and operational decisions around nutrient management in the field. However, experience shows us that nutrient management outcomes are influenced by several factors across many scales, most uncontrollable, which must be considered when transferring science into policy and when establishing realistic public expectations. Key factors influencing these nutrient management concepts, complexities, inherent tradeoffs, and outcomes are summarized in table 1 and are discussed in more detail in this article.

Nutrient use efficiency for both nitrogen $(\mathrm{N})$ and phosphorus $(\mathrm{P})$ has increased steadily over the last two decades, with advances in crop breeding, soil and crop tissue testing, variable rate application of fertilizer, precise fertilizer applications, and precision conservation. The increase in NUE and adoption of nutrient management and conservation practices (CPs) has

Andrew Sharpley is a distinguished professor in the Department of Crop, Soil and Environmental Sciences, Division of Agriculture, University of Arkansas, Fayetteville, Arkansas. Matthew J. Helmers is dean's professor in the Department of Agricultural and Biosystems Engineering, lowa State University, Ames, lowa. Peter Kleinman is a soil scientist and Research Leader, USDA Agricultural Research Service (ARS), Pasture Systems and Watershed Management Research Unit, University Park, Pennsylvania. Kevin King is an agricultural engineer and research leader, USDA ARS, Soil Drainage Research Unit, Columbus, Ohio. April Leytem is a research soil scientist, USDA ARS, Northwest Irrigation and Soils Research Laboratory, Kimberly, Idaho. Nathan Nelson is a professor in the Department of Agronomy, Kansas State University, Manhattan, Kansas. led to a reduction in nutrient loss. While adoption of these practices to address socalled "low hanging fruit" can be relatively easy and cost-effective, what comes next to extend nutrient loss reductions continues to be an economic and logistical challenge to the agricultural community. This challenge is heightened by the fact that we know that loss of agricultural nutrients in edge-of-field runoff, albeit small (especially for $\mathrm{P}$ ) can, in aggregate, accelerate eutrophication of receiving waters (Daniels et al. 2018; Smith et al. 2016).

\section{NUTRIENT SOURCES}

Nonpoint sources of agricultural nutrients vary widely and are dependent upon many factors, from native soil properties, to land use, to management intensity. Over the last several decades, advances in plant genetics/genomics and crop management have increased crop yields and improved NUE, which can decrease the nutrient quantity remaining in the soil following crop harvest. Additionally, implementation of nutrient management practices, such as following the $4 \mathrm{R}$ principles of applying nutrients at the right rate, in the right place, at the right time, and with the right source, has played a major role in reducing nutrient loss, and is based on a large amount of research to address $\mathrm{N}$ and $\mathrm{P}$ loss. However, a significant portion of that research was focused on a single nutrient rather than investigating collectively. Unintended consequences have resulted, as addressing one issue can directly or indirectly exacerbate a second.

Nutrient Use Efficiency. Nutrient use efficiency can be defined in different ways and applied at various scales, from field to farm to commodity production system (Fixen et al. 2015; Moll et al. 1982). In general, NUE is calculated as the amount of nutrient taken up by the crop divided by the amount of nutrient available to be taken up. Often the numerator is simply a fraction of the nutrient taken up (e.g., that taken up in grain, the increased uptake due to fertilization, etc.), and the denominator is simply a fraction of the total quantity available for uptake (e.g., nutrient supplied by fertilization). Although NUE is useful for comparing the agronomic efficiency of cropping systems and management, it is less useful for comparing the risk of water quality degradation resulting from changes in management. This is because NUE is focused on assessing the amount of nutrient in the crop, not the amount of nutrient lost to water.

Nutrients that are not taken up by the crop are subject to a wide range of potential fates and transformations including incorporation into soil organic matter (immobilization), reaction with soil surfaces (adsorption), reaction with other cations or anions (precipitation), or gaseous losses (e.g., denitrification or volatilization in the case of N). Each of these processes could decrease NUE while simultaneously decreasing the amount of nutrient available for loss to water. Furthermore, management practices could increase NUE by increasing the fraction of available nutrient taken up by the crop, but leave the amount available for loss to water unchanged or even increased. For example, decreasing $\mathrm{N}$ volatilization could increase NUE by increasing the amount of $\mathrm{N}$ available in the soil for plant uptake, but this could also increase the amount that could potentially be lost to water through leaching.

Currently it is estimated that $47 \%$ of added reactive $\mathrm{N}$ remains present in harvested products globally (Lassaletta et al. 2014). While crop yield per unit of $\mathrm{N}$ has been increasing since 1960 in the United States, $\mathrm{N}$ removal per unit of $\mathrm{N}$ applied has remained relatively unchanged since 1980 (Lassaletta et al. 2014). Nitrogen that is not removed in the harvested crop may remain in the soil with nonharvested crop portions (roots and residue), remain in soil as nitrate $\left(\mathrm{NO}_{3}^{-}\right)$or ammonium $\left(\mathrm{NH}_{4}^{+}\right)$, become immobilized by soil microorganisms, move to the atmosphere through volatilization or denitrification, or move to ground or surface water through leaching. Because crops are not $100 \%$ efficient at taking up nutrients from soil, there will always be some 


\section{Table 1}

Glossary of key nutrient management concepts, related considerations, inherent tradeoffs, and outcomes.

Concept

Key considerations and complexities

Nutrient use efficiency (NUE) • A useful concept for comparing agronomic efficiency of production systems, but is not the end all for water quality.

- Education and support for nutrient users is highly variable from state to state.

- Despite the significant gains in NUE (i.e., the amount of nutrient utilized by a crop per unit of nutrient input into the system), farmers face considerable challenges with monitoring, measuring, and otherwise demonstrating progress and the effectiveness of nutrient management measures.

Inherent vulnerability of $\quad$ Inherent vulnerability of a site to nutrient loss is based upon site properties (proximity/connectivity to receiving landscapes to nutrient loss $\quad$ water, vulnerability to runoff/erosion).

- Not all sites have an equal propensity to contribute nutrients to receiving waters (especially over the short term).

Tile drainage and nutrient flux • The more connected the system is to water, the greater the risks to have transport.

- Nutrient transport from tile-drained fields present unique challenges and, thus, solutions.

- The concept of "bypass" or rapidly moving drainage water through a network of underground pipes is equally important for nitrogen $(\mathrm{N})$ and for phosphorus ( $\mathrm{P}$; and part of connectivity).

- Artificial drainage systems introduce features that may seem minor through the perspective of a water balance, but bypass the buffers that exist naturally along flow paths.

- Connectivity includes a temporal dimension. Quick flows for P decrease the ability for it to be retained within the soil profile, along riparian areas, and within stream networks.

- Losses of $\mathrm{P}$ in tile drainage, albeit small compared with other pathways, can be sufficient to accelerate eutrophication of receiving water.

Weather as a nutrient $\quad$ Hydrology is governed by weather.

loss driver - Weather/climate is an unmanageable, yet major driver of nutrient losses.

- On a short time scale, weather is the main driver of NUE and nutrient runoff (i.e., surface and subsurface). As time scales get longer, management becomes the primary driver.

- Largest percentage of transport occurs with largest precipitation events.

- Seasonality determines the importance of snowmelt in northern latitudes; this also may apply to expectation of downstream impact.

Conservation tradeoffs in - Conservation practices that decrease the loss of $\mathrm{N}$ can increase the loss of $\mathrm{P}$ and vice-versa.

nutrient loss $\quad$ - Flexibility in nutrient management, as well as adaptive, targeted, and precision conservation are essential to minimizing tradeoffs.

- Attention and effort must be given to these unintended consequences to avoid such losses and tradeoffs, and, if possible, find synergies.

Legacies of prior nutrient $\quad-\quad$ Lag times for nutrient fate and transport range from annual to decadal time scales.

management - L Lag times for $\mathrm{N}$ tend to be controlled by diverse landscape and watershed hydrologic pathways; while $\mathrm{P}$ lags are influenced by management factors that result in rapid build-up countered by appreciably longer declines via plant offtake of soil P.

- Lag times must be taken into consideration both in setting expectations for measuring the performance of nutrient management practices and on policy outcomes.

Snowmelt runoff as a $\quad$ - In northern regions, where ground freezes, snowmelt plays a significant role in dissolved $\mathrm{P}$ loss from

source of nutrient loss agricultural landscapes.

- More effort is needed to quantify snowmelt-driven losses and identify nutrient and conservation management strategies that mitigate impairment.

Nutrient management as a • There is no "one-size-fits-all" approach to nutrient management.

conservation practice - Retaining flexibility and adaptability is critical.

- Continued assessment of effectiveness via soil testing and edge-of-field runoff monitoring is essential.

Measures to achieve desired • The most important measures are going to be site-specific and should include the 4Rs of fertilizer management. nutrient loss reductions and - Additional measures include, but are not limited to, conservation tillage, cover crops, managed flows from mitigate their effects artificially drained landscapes, edge-of-field bioreactors, and strategic use of natural and constructed wetlands.

Critical source area

- "Hotspots" of nutrient loss from landscapes need additional attention.

management remains a priority - Critical source areas of $\mathrm{N}$ tend to be watershed based as related to hydrology and nutrient management. For $\mathrm{P}$, these areas tend to be at the confluence of high source and transport across landscapes.

- For instance, most states have developed, adopted, and require P Indexing risk assessment to identify, quantify, and target nutrient management and other conservation practices to mitigate critical source area losses of $P$.

- Focused rather than broad watershed based nutrient management and conservation strategies are needed to address critical source areas.

nutrient remaining in soil following crop harvest or lost to the environment.

It is estimated that only $15 \%$ to $30 \%$ of applied fertilizer $\mathrm{P}$ is taken up by crops in the year of its application (Syers et al. 2008). Phosphorus use efficiency within a year can be very low due to a variety of reactions that occur in soils that may limit its solubility. Phosphorus remaining in the soil may be recovered in future years or may be subject to loss to the environment. Although $\mathrm{P}$ recovery may be low when 


\section{Table 1 continued}

\begin{tabular}{|c|c|}
\hline Concept & Key considerations and complexities \\
\hline $\begin{array}{l}\text { In-stream nutrient inputs can } \\
\text { mask the benefits of } \\
\text { in-field conservation }\end{array}$ & $\begin{array}{l}\text { - Nutrient inputs from streambank erosion and in-stream fluvial cascading have varied and important contributions } \\
\text { to watershed nutrient fluxes. This is particularly true for P. } \\
\text { - These post-field losses can mask the benefits of nutrient loss reductions imparted by in-field implementation of } \\
\text { conservation practices. } \\
\text { - Accounting for the influence of streambank losses and other natural and nonfarm sources of nutrient losses are } \\
\text { critical to crafting sound and effective policies at a watershed scale. }\end{array}$ \\
\hline $\begin{array}{l}\text { Managing system uncertainty } \\
\text { and expectations }\end{array}$ & $\begin{array}{l}\text { - The role of uncertainty of climate fluctuations in dominating nutrient loss at an annual and watershed basis } \\
\text { continues to be a challenge to address. } \\
\text { - "Zero-loss" of nutrients from a watershed is unlikely to be achieved in a productive agricultural setting. } \\
\text { - Some attention should be given to quantifying the tradeoffs between surface runoff of nutrients from undrained } \\
\text { fields and losses from artificially drained fields. }\end{array}$ \\
\hline $\begin{array}{l}\text { The role of monitoring and } \\
\text { modeling in nutrient } \\
\text { management and loss } \\
\text { assessment }\end{array}$ & $\begin{array}{l}\text { - In-field, edge-of-field, and downstream monitoring is essential to determine the effects of nutrient and } \\
\text { conservation management. } \\
\text { - However, monitoring is expensive, laborious, and requires increasing length of time as the spatial scale of } \\
\text { assessment increases to obtain reliable outcomes for future recommendations. } \\
\text { - Process-based and empirical models must be locally calibrated and validated prior to use in providing qualitative } \\
\text { relative comparisons of nutrient and conservation management on nutrient fate and transport. }\end{array}$ \\
\hline
\end{tabular}

evaluated over short time frames, the persistence of fertilizer $\mathrm{P}$ in soils combined with the drastic decline in crop yields when $\mathrm{P}$ is not supplied results in $\mathrm{P}$ recoveries of over $60 \%$ in long-term studies (Schlegel and Havlin 2017).

Use of fertilizer P, while improving the fertility of previously P-deficient soils, has enabled continued food production without efficiently recycling $\mathrm{P}$ that is excreted by humans and livestock or is contained in other organic wastes back to farm fields. Because of this, the typical flow path of $\mathrm{P}$ moves from rock phosphate mines to distant locations for crop production and then to different areas for livestock and human consumption (Jarvie et al. 2015). As a result, animal, food, and human wastes are rarely returned to areas of crop production. Ultimately, sustainable use of $\mathrm{P}$ will require adjustments that promote its recycling and reuse, something that is currently cost-prohibitive.

Enhancing Nutrient Use Efficiency as a Mitigation Strategy. There are a variety of factors that may enhance or reduce NUE at the field scale. The source of the nutrient can have a large impact on its solubility, plant availability, and potential for losses to the environment. The use of fertilizers, while providing a source of readily available nutrients, may be susceptible to leaching and runoff losses if not utilized by the plant during the growing season. Manures and other organic sources can become available over time as organic forms of $\mathrm{N}$ are mineralized throughout the growing season (Lehrsch et al. 2016). Late season release of nutrients can enhance losses from the system, as they may not be utilized by crops. Additionally, use of organic nutrient sources with low N:P ratios in some cases result in significant $\mathrm{P}$ surpluses (Maltais-Landry et al. 2016). The development of controlled or slow release fertilizers can help reduce environmental losses, as nutrients are released slowly over time and may better match plant uptake patterns (Yang et al. 2012). Other factors that affect NUE include timing of application, irrigation and water management, crop rotations, plant health, genetics, and the overall balance of $\mathrm{N}, \mathrm{P}$, and potassium (K) available in the soil (Quemada et al. 2013; Halvorson and Bartolo 2014; Woli et al. 2016).

Nitrogen fertilizer application closer to planting (Rens et al. 2016) or utilizing in-season applications of nutrients when most needed by the plants (Jaynes 2015; Zotarelli et al. 2015) can enhance overall NUE and reduce losses to the environment, especially for N. In addition, fertilizer placement can enhance plant availability and retention of $\mathrm{N}$ in the soil profile (Siyal et al. 2012). In-field water management can also have large impacts on nutrient losses, particularly for N. Over irrigation can reduce NUE as $\mathrm{N}$ is flushed out of the root zone, and drought can also reduce plant uptake of $\mathrm{N}$. Adjusting $\mathrm{N}$ fertilizer rates based not only on crop requirements but on the amount of irrigation water applied can increase yields and reduce $\mathrm{N}$ losses particularly in arid regions (Kiani et al. 2016; Mon et al. 2016).

New programs, such as the $4 \mathrm{R}$ Plus program in Iowa (https://www.4rplus. $\operatorname{org} /$ ), where "Plus" refers to addition of $\mathrm{CPs}$, can boost production, increase soil resiliency, reduce erosion and runoff, and improve water quality in addition to earlier mentioned $4 \mathrm{R}$ nutrient management (IDALS et al. 2012). The 4R Plus program encourages producers to adopt practices that will both increase NUE and decrease the environmental impact of nutrients. Of note relative to the $4 \mathrm{Rs}$, as producers strive to attain optimal timing for nutrient application, they may inadvertently place additional stresses and challenges on companies responsible for fertilizer logistics, storage, and transport. Furthermore, additional field operations may need to be added as optimal timing for $\mathrm{N}$ and $\mathrm{P}$ applications are often different, therefore nutrients that were co-applied may require their own application operation.

Utilizing crop rotations that maximize overall nutrient use can also be beneficial (Tonitto et al. 2006; Pikul et al. 2012). For example, incorporating wheat (Triticum aestivum L.) as a component of maize (Zea mays L.)/soybean (Glycine max [L.] Merr.) rotations can increase maize and soybean productivity while using less $\mathrm{N}$ input (Gaudin et al. 2015). This may also include rotations with $\mathrm{N}$ fixing crops and 
cover crops. Research indicates that careful selection of these rotations can enhance overall NUE in many cases. Overall plant health will have an impact on NUE as lower yields due to disease or insect pressure will reduce overall biomass production and, therefore, nutrient removal from the system. Improving root growth can improve crop yield, increase NUE, and reduce nutrient runoff (Caires et al. 2016). Improvement in genetics can enhance overall NUE by increasing yields or in some cases increasing the plant's ability to extract nutrients from soil or utilize other forms of nutrients (Reeve et al. 2009; Richardson et al. 2011; Chen et al. 2015; Woli et al. 2016).

Ensuring proper balance between N, P, and $\mathrm{K}$ can also enhance overall NUE as a limitation in one of the essential nutrients can hinder utilization of the other nutrients (Marti et al. 2002; Duan et al. 2014). For example, increasing available soil $\mathrm{P}$ was shown to increase $\mathrm{N}$ use efficiency by 25\% to $45 \%$ in maize (Duan et al. 2011). Utilization of "legacy" $\mathrm{P}$ in systems with a history of over application of $\mathrm{P}$, can also be beneficial but requires a holistic approach to nutrient management (Rowe et al. 2016).

Although achieving high NUE at the field scale can be beneficial, overall improvements in NUE at broader scales may not improve. For instance, if one looks at both the fertilizer and manure $\mathrm{N}$ and $\mathrm{P}$ available across the United States, it is apparent that nutrient surpluses exist in many regions. This is particularly true for areas with concentrated livestock production coupled with crop production. Improvement in regional NUE in these systems will only be achieved through better integration of livestock cropping systems with optimal recycling of manure nutrients (Powell et al. 2017). Long-term improvements in regional water quality will not likely be achieved until these larger scale issues in nutrient cycling are addressed.

As discussed above, many of the weather, management, and crop factors that contribute to improvements in NUE can also contribute to decreases in nutrient loss. Some data do indicate that improvements in NUE are correlated with improvements in water quality. For example, McIsaac et al. (2016) found a decreasing trend in residual $\mathrm{N}$ (or improved NUE) that occurred during the same period in which decreased flow-weighted $\mathrm{NO}_{3}^{-}$concentration was observed for the Illinois River. In a comprehensive meta-analysis of $\mathrm{N}$ losses from irrigated corn, Quemada et al. (2013) found that reduced $\mathrm{N}$ application rates both increased $\mathrm{N}$ use efficiency and decreased $\mathrm{NO}_{3}^{-}$leaching.

However, the same studies found instances where improved NUE was not correlated with decreased nutrient losses or improvements in water quality. McIsaac et al. (2016) found that improvements in NUE did not decrease the $\mathrm{N}$ load leaving the Illinois River watershed even though there were decreases in $\mathrm{NO}_{3}^{-}$concentrations. Quemada et al. (2013) found that changing the optimal timing of fertilizer application did not improve $\mathrm{N}$ use efficiency, although it did decrease $\mathrm{NO}_{3}{ }^{-}$leaching losses. They also found that using a legume cover crop increased corn yield and $\mathrm{N}$ use efficiency but did not reduce $\mathrm{NO}_{3}^{-}$leaching. On the contrary, using a non-legume cover crop had no impact on corn yield or $\mathrm{N}$ use efficiency despite reducing $\mathrm{NO}_{3}^{-}$leaching per unit of yield by $70 \%$.

The lack of consistent relationships between NUE and nutrient loss is because increases in NUE only indicates a reduction in the amount of nutrient that can potentially be lost, but other factors influence actual loss. In addition, some management factors, such as cover crop use, edge-of-field buffers, or controlled drainage, can have substantial impacts on nutrient losses but no impact on NUE. It is important to note that NUE is not a measure of nutrient loss and there are situations where systems with high NUE may still have environmentally significant nutrient losses (Fixen et al. 2015), as well as other situations where systems with low NUE may have very low losses.

\section{TRANSPORT}

Hydrologic Controls. Agricultural production in both rainfed and irrigated environments occur in inherently "leaky" systems; that is, excess water will exit the system through either surface runoff or leachate. Nutrient transport is controlled by hydrology, whether in arid, irrigated systems or humid, artificially drained landscapes. In more arid environments, hydrology is often governed by the introduction of water through irrigation. In humid areas, natural precipitation is the driver for nutrient transport.

Nutrient transport is often more pronounced in areas where connectivity to water is more prevalent (i.e., artificially tile-drained and irrigated systems). However, adverse environmental impacts related to offsite nutrient transport have been measured in irrigated systems of arid and semiarid climates. Additionally, significant losses have been found to have a seasonal pattern, which often follow wetter periods or snowmelt or during the irrigation season. These losses can be exacerbated when vegetative cover is limited and critical nutrient management and tillage operations occur, which is typically when the agricultural system is most susceptible to losses.

Tile Drainage. In the humid, poorly drained regions of the world, subsurface (tile) drainage is necessary for (a) ensuring field access for farming operations, (b) decreasing soil compaction, (c) limiting potential water stress, (d) reducing susceptibility to pests and diseases, and (e) promoting more uniform crop production (Spaling and Smit 1995; Kornecki and Fouss 2001; Fausey 2003, 2005; Blann et al. 2009; King et al. 2015). In the Midwest United States, greater than 28 million ha (69 million ac) of land benefits from subsurface tile drainage, while in Canada approximately 8 million ha (20 million ac) are artificially drained (Zucker and Brown 1998; Shady 1989). More recent estimates suggest that the extent of tile drainage is significantly greater (Sugg 2007) and that the density of tile drainage continues to increase (Blann et al. 2009).

Tile discharge is governed by several factors that include site-specific characteristics (e.g., hydraulic conductivity and management), tile system design (i.e., depth and spacing), precipitation characteristics (e.g., volume, duration, and intensity), and antecedent soil moisture conditions (Heppell et al. 2002; King et al. 2014, 2015; Smith et al. 2015). The presence of tile drainage generally increases the storage holding capacity of soil between subsequent rainfall events, decreasing the 
potential for surface runoff and dampening stream-scale peak discharge rates (Skaggs and Broadhead 1982; Skaggs et al. 1994). However, in other studies, peak stream discharges have been demonstrated to increase with tile drainage (Wiskow and van der Ploeg 2003). When compared to sites with no tile drainage, total field-scale discharge has been shown to increase by $10 \%$ to $25 \%$, and the timing of that discharge is substantially altered (Serrano and Irwin 1985; Magner et al. 2004; Tomer et al. 2005; Blann et al. 2009).

Tile drainage has been identified as a significant pathway for both $\mathrm{N}$ and $\mathrm{P}$ transport (Sims et al. 1998; Dinnes et al. 2002; King et al. 2015). Nitrogen losses tend to be in the form of $\mathrm{NO}_{3}^{-}$, while $\mathrm{P}$ losses are both dissolved and sediment bound. Nitrogen concentrations from tile drainage average 12 to $16 \mathrm{mg} \mathrm{L}^{-1}$ (David et al. 1997) with maximums exceeding $30 \mathrm{mg} \mathrm{L}^{-1}$ (Jaynes et al. 1999; Kaspar et al. 2007). On the other hand, mean $\mathrm{P}$ concentrations from tile drainage are generally two orders of magnitude less than $\mathrm{NO}_{3}^{-}$, with peaks roughly an order of magnitude less (King et al. 2015; Pease et al. 2018). Additionally, in either the case of $\mathrm{N}$ and/or P, these concentration levels can contribute to harmful algal blooms and hypoxic zones in surface waters, regardless of the source of nutrients. However, tile drainage should not be the sole focus. The combined (surface + tile) magnitude of loss, at least for P, may actually be less in the presence of tile drainage. Phosphorus concentrations in surface runoff have been shown to be two to five times greater than those in tile drainage discharge (Pease et al. 2018). Thus, even with larger discharges through tile drainage, the overall loading is likely less than it would be if the discharge originated solely from surface runoff.

It should also be noted that tile drainage can serve as a conduit for moving nutrients from field to stream. Because the excess water is transported through a network of drainage pipes rather than naturally through stream buffers, the opportunities for denitrification and $\mathrm{P}$ adsorption by the soil matrix have been decreased. As a result, CPs that mimic these attenuation properties via constructed wetlands are being assessed and gaining acceptance in
Midwest agricultural landscapes (Allred et al. 2014; Kovacic et al. 2000, 2006).

Much research has focused on how to address or reduce the loss of $\mathrm{N}$ in tile drainage (Christianson et al. 2016) but for $\mathrm{P}$, research is more in its infancy as $\mathrm{P}$ movement through tile drainage was thought to be negligible (Baker et al. 1975). There is a need for continued research work on $\mathrm{P}$ movement through drainage systems under different soil conditions across the Corn Belt (King et al. 2015).

Mitigation Strategies for Nitrogen

Reduction. A multistate effort was initiated and resulted in a summary of practices to reduce $\mathrm{N}$ losses from tile-drained landscapes (Christianson et al. 2016). The authors grouped practices into three categories of practices to (a) reduce $\mathrm{NO}_{3}^{-}$in the root zone, (b) reduce delivery to the field edge, and (c) remove $\mathrm{NO}_{3}^{-}$at the edge-of-field or downstream (Christianson et al. 2016).

Practices to reduce $\mathrm{NO}_{3}^{-}$in the root zone include improved $\mathrm{N}$ management, winter cover crops, and increasing perennials in the cropping system. At the heart of improved $\mathrm{N}$ management is the $4 \mathrm{R}$ approach (Fixen 2007; Roberts 2007). Within the $4 \mathrm{R}$ approach, applying $\mathrm{N}$ at the right rate has the greatest potential for reducing $\mathrm{N}$ loss through tile drainage. For example, Christianson et al. (2016) showed that field trials from Iowa trended very well with the drainage flow response curve developed by Lawlor et al. (2008). If considering all conservation management approaches, introducing cover crops may have the greatest potential to address $\mathrm{N}$ loss. Planting cover crops significantly reduced (13\% to $94 \%) \mathrm{NO}_{3}^{-}$concentrations in tile drainage (Kaspar et al. 2008), while the introduction of perennials, such as alfalfa (Medicago sativa L.), showed a substantial reduction in tile $\mathrm{NO}_{3}^{-}$concentration and loading in Minnesota (Randall et al. 1997; Christianson et al. 2016).

Practices such as drainage water management or controlled drainage (Frankenberger et al. 2007), reduced drainage intensity (Kladivko et al. 2004), and recycling drainage water (Allred et al. 2014) also reduce $\mathrm{N}$ delivery at the field edge. Drainage water management is the practice of artificially raising the outlet elevation of a tile. When compared to free drainage across multiple studies, drainage water management has been shown to reduce $\mathrm{NO}_{3}^{-}$loss from tile drainage by approximately 50\% (Ross et al. 2016). Drainage design also affects $\mathrm{NO}_{3}^{-}$delivery. In general, the wider the spacing the less $\mathrm{NO}_{3}{ }^{-}$delivery (Kladivko et al. 2004). Similarly, the deeper that drains are placed in the soil, the more $\mathrm{NO}_{3}{ }^{-}$delivery (Sands et al. 2008). Therefore, to reduce $\mathrm{NO}_{3}{ }^{-}$ loading, producers can increase the drain spacing and reduce the depth of placement (Christianson et al. 2016). Routing drainage water to storage basins and recycling the water also shows promise in reducing $\mathrm{NO}_{3}^{-}$loads (Allred et al. 2014; Christianson et al. 2016). The primary mechanism is the reduction of drainage discharge to surface water bodies through increasing on-site water storage. Drainage water recycling demonstrations in Ohio showed a $36 \%$ reduction in $\mathrm{NO}_{3}^{-}$load (Allred et al. 2014).

Nitrogen removal at the field edge or downstream can be accomplished through woodchip bioreactors (Christianson et al. 2012), wetlands (Crumpton 2001; Crumpton et al. 2006), alternative openditch design (Powell et al. 2007; Mahl et al. 2015), and saturated buffers (Jaynes and Isenhart 2014). Woodchip bioreactors enhance denitrification and have been shown to reduce field-scale $\mathrm{NO}_{3}^{-}$loading from $12 \%$ to $98 \%$, with average annual reductions approximately $30 \%$ to $40 \%$ (Christianson et al. 2012, 2016). Wetlands also promote denitrification and dampen downstream flow. In Illinois and Iowa, routing tile drainage through wetlands has reduced $\mathrm{NO}_{3}^{-}$loading from 16\% to $78 \%$ (Kovacic et al. 2000, 2006; Crumpton et al. 2006). Alternative ditch design takes advantage of increasing floodplain interaction allowing for denitrification and plant uptake. Nitrate removal across several discharge events was less than $10 \%$ but was significantly greater for smaller discharge volumes (Roley et al. 2012). Saturated buffers take advantage of reconnecting tile drainage to the buffer. Significant reductions in $\mathrm{NO}_{3}^{-}$load should be expected as the discharge is routed into the buffer and not allowed to directly enter surface water. 
Mitigation Strategies for Phosphorus Reduction. While no single compilation of practice recommendations exists for addressing $\mathrm{P}$ in tile drainage, several studies point to directionally correct practices, some of which overlap with those identified for addressing $\mathrm{N}$ loss. Practices providing the most promise for reducing $\mathrm{P}$ from tile drained landscapes include upland practices such as the 4Rs (Roberts 2007; Fixen 2007) and water management practices (e.g., drainage water management [Frankenberger et al. 2007], blind inlets [Smith and Livingston 2013], enhanced water storage capacity [Hudson 1994], P filters [Penn et al. 2012], and alternative ditch design [Powell et al. 2007; Mahl et al. 2015]). Within the 4R framework, soil testing (Sharpley et al. 2001; Maguire and Sims 2002; Duncan et al. 2017 ), subsurface placement (Williams et al. 2016), and timing of application (Schroeder et al. 2004; Smith et al. 2007; King et al. 2018) have all been shown to reduce P loss in tile drainage. Historical recommendations for $\mathrm{P}$ fertility focused on a build and maintain philosophy, which has led to large $\mathrm{P}$ stores in many fields (Jarvie et al. 2013; Withers et al. 2014). Soil testing at least once in the rotation and adhering to those recommendations will create a change in philosophy from "build and maintain" (i.e., "feed the soil") to a "feed the crop" mentality, which, in time, should reduce the chronic losses of $\mathrm{P}$ (Withers et al.2014; King et al. 2018).

Likewise, placing $\mathrm{P}$ below the surface and getting $\mathrm{P}$ in contact with the soil also reduces tile losses. For example, Williams et al. (2016) measured a five-fold decrease in peak dissolved $\mathrm{P}$ concentration and a seven-fold decrease in dissolved P load from tile drainage when fertilizer was lightly incorporated compared to surface broadcast application. Furthermore, applying $\mathrm{P}$ during periods with dry antecedent conditions and/or low probability for large erosive precipitation events can substantially reduce tile drainage $\mathrm{P}$ losses. In addition, extending the time from application to first rainfall after application can significantly reduce P concentrations (Schroeder et al. 2004; Smith et al. 2007). While it is extremely difficult to quantify the specific individual effects of several conservation measures when used in combination, a directionally correct change occurs (Kleinman et al. 2017; Sharpley et al. 2015).

Discharge has been identified as the primary control mechanism for P movement (Williams et al. 2016). Thus, disrupting the hydrologic pathways or storing more water in the landscape is a logical means to reduce the amount of $\mathrm{P}$ delivered through tile drainage. Practices such as drainage water management or controlled drainage (Frankenberger et al. 2007) have been shown to reduce the amount of $\mathrm{P}$ loss through tile drainage by greater than $50 \%$ primarily through a reduction in drain flow (Williams et al. 2015; Ross et al. 2016). However, there are still research questions concerning where the water goes if it is not coming out of the drain. Additionally, if, as some modeling suggests, it results in increased surface runoff, this would minimize the benefits of drainage water management for $\mathrm{P}$ reduction. Drainage water recycling is a practice that has potential for $\mathrm{P}$ reduction but additional research is needed to quantify potential benefits.

Due to topographic constraints, drainage water management cannot be implemented on all fields. In fields with closed depressional areas, the normal practice is to install a riser pipe that transports surface runoff through the tile drainage network. Smith and Livingston (2013) addressed this by removing the surface riser and installing a "reverse leach field" or blind inlet. Slowing the discharge and trapping the sediments rather than transporting them reduced the dissolved and total P loss by approximately $60 \%$. Another recommended practice for increasing water storage capacity is cover crops and no-till. While cover crops themselves have been identified as a scavenger for $\mathrm{N}$, the results for $\mathrm{P}$ are not as promising. In fact, due to freeze thaw cycles, more P may be lost from cover crops than without. However, the advantage of no-till and cover crops lies in the development of soil organic matter and carbon (C) along with decreased soil loss. Through no-till and cover crops, soil organic matter can be increased. For every 1\% increase in organic matter and depending on soil tex- ture, approximately 18 to $20 \mathrm{~mm}$ (0.71 to 0.79 in) of water can be stored in the soil (Hudson 1994).

Phosphorus filters (Penn et al. 2012) and alternative ditch design (Powell et al. 2007; Mahl et al. 2015) are two practices that can help to trap or reduce $\mathrm{P}$ that has moved to the field edge or into the drainage ditch network. Phosphorus filters are often constructed at the end of a concentrated flow path or tile drainage and are comprised of some $\mathrm{P}$ sorbing material (e.g., steel slag) (Stoner et al. 2012). Phosphorus reductions in surface waters have been measured at greater than $25 \%$ (Penn et al. 2012). Testing in tile-drained landscapes is ongoing, and preliminary data suggest similar or better results. Alternative ditch design also shows promise for reducing $\mathrm{P}$ losses once in the ditch network. Measurements from a two-ditch in Indiana showed a $3 \%$ to $53 \%$ reduction in dissolved $\mathrm{P}$ concentrations (Mahl et al. 2015). Normal ditch maintenance or dredging has also been demonstrated to convert agricultural ditches from sources to sinks, but the benefit lasts for only a year (Smith and Huang 2010).

Overcoming Legacies. Gaps in our current knowledge require further research. These gaps include (a) a more holistic understanding of subsurface hydrology, (b) effects of single, multi, and/or stacked upland and edge-of-field management or CPs and the associated tradeoffs, (c) development and enhancement of prediction/ simulation tools, (d) impacts of soil quality on water quality, and (e) legacy $\mathrm{N}$ and $\mathrm{P}$ pools. Nutrients move with water. Thus, a clearer hydrologic understanding in poorly drained soils with a propensity for developing preferential flow paths is warranted. Further, most studies limit their data collection to the growing season. Year-round data collection is needed to fully understand water and nutrient balances in tile-drained landscapes and develop/design practices.

Every year, millions of dollars are devoted to promoting and implementing CPs. However, in many cases these practices have not been widely tested temporally, spatially, or economically. While they may be directionally correct, they may or may not provide significant reduc- 
tions in $\mathrm{N}$ and $\mathrm{P}$ losses. Improvements in simulation technologies are needed to better estimate the impacts of management in tile drained areas. Most of the currently available simulation tools do not adequately represent tile drainage or the processes associated with water movement into and through tile drainage systems. In addition, the models that do represent tile drainage are more advanced in their simulation of the $\mathrm{N}$ cycle and there is a critical research need for model development relative to $\mathrm{P}$ leaching.

Much emphasis today is being placed on soil quality and rightly so, as our soil resources are finite. However, there is also an unsubstantiated leap being made to equilibrate good soil quality/health with good water quality. There is currently no or very limited data to support this often "gospel" correlation. Finally, and maybe more related to $\mathrm{P}$ than $\mathrm{N}$, there is a large knowledge gap in understanding the relationship between historical fertilizer applications and current water quality. Since the 1970s, P has been applied at recommended rates. However, due to the inefficiency of $\mathrm{P}$, much of that application has built up in the soil creating large $\mathrm{P}$ reserves. More research is needed on how that large $\mathrm{P}$ pool is made available and if those dynamics are microbially mediated or change with farming practice. Furthermore, only limited information is available on nutrients stored in field borders, streambanks, and streambeds (Dodd and Sharpley 2016).

An important factor relative to nutrient loss and CP is the timing of when loss occurs. For example, drainage losses in the northwestern Corn Belt are more in the spring of the year with some in the fall while in the southeastern Corn Belt more of the drainage occurs during the nonfrozen winter period (Christianson et al. 2016). In addition, in certain areas of the Corn Belt the snowmelt period may be one of the most critical nutrient transport periods and would need to be factored into CP implementation.

A critical factor in both implementation of practices and in assessment is the vulnerability of the site to nutrient loss, which needs to consider the site properties, connectivity or potential for nutrient loss to a downstream water body, and changing weather patterns. A site close to the stream with significant slope would have greater potential for nutrient delivery to a downstream water than a relative flat field some distance from a water body. However, artificial connectivity also needs to be considered. For example, leaching losses from a specific site can be carried by subsurface drainage systems to downstream waterbodies such that these fields are closely connected to the receiving waters even if they are some distance away. In irrigated systems, a network of return flow channels may transport runoff from distant fields directly to receiving water bodies. This potential for delivery of nutrients from the individual field to the stream is important for planning and implementation of conservation systems.

\section{MANAGEMENT STRATEGIES}

As described above, the cycling, or transfer, of nutrients in agriculture production systems transcends many scales, all of which may influence local outcomes, impacting the use of nutrients by crops and livestock and the fate of nutrients in the environment. Therefore, as producers work to implement production systems that are more efficient and pose fewer external consequences, there are limits to what may be expected from changes in management at any scale. Further, the nutrient management challenges facing agriculture extend beyond technology, and must be seen in broader contexts, from socioeconomic constraints to practice adoption, to factors affecting commodity pricing, to policy. There is, however, strong consensus that major opportunities exist for improvements in nutrient management across all production systems, even those with limited options to accommodate the economic and labor constraints of management decisions.

Nutrient Management. Management of nutrient loss from watersheds requires an understanding of the causes of pollution, which can be complex and even poorly identified (especially as watershed scale increases). Indeed, site-specific contexts often confound quick fixes based upon generalizations. When developing watershed mitigation strategies, it is important to differentiate between concerns related to the loss of sediment-bound nutrients (e.g., particulate $\mathrm{P}$ and $\mathrm{N}$ ), which can be effectively addressed with soil conservation and erosion control strategies, and the loss of soluble nutrients (e.g., dissolved $\mathrm{P}$ and $\mathrm{NO}_{3}^{-}$), which requires source management along with additional approaches, many experimental. In general, control of sediment sources is the initial priority in watershed implementation plans, followed by targeted application of strategies to control soluble losses. With few exceptions, an iterative approach to management strategies has proven to be most effective, adapting to lessons learned from stakeholders and scientists alike, modifying initial strategies, and reprioritizing investments (Osmond et al. 2012).

Major strides have been made in packaging nutrient management for water quality mitigation in ways that make it easier to convey and often more palatable. Specifically, the $4 \mathrm{R}$ strategy promoted by industry, government, university, and other organizations provides a framework for tackling the complex interactions within nutrient management decisions.

Included within the $4 \mathrm{R}$ principles of nutrient management stewardship is the concept of right rate, that is, the application of nutrients to soils at rates that meet crop demand and do not jeopardize environmental factors such as water quality. Recognizing when there are sufficient soil nutrients for crop production is different from planning long-term nutrient management strategies, and there are often conflicts in strategies that focus upon mass-balance approaches to nutrient management and strategies that weigh other priorities in production. While flexibility in planning is essential to ensuring that nutrient management is not only practical, but can actually be adopted by farmers, there are conditions where flexibility cannot be accommodated.

Hydrology and Critical Source Area Management. Watershed management strategies must consider the degree of hydrologic activity (surface and subsurface) and connectivity to stream networks. The critical source area approach to management is well accepted in the United States and elsewhere, targeting areas where 
both concentrated sources and high transport potential coincide. This reasonable approach supports cost-effective watershed strategies for nutrient management. It also acknowledges that applying nutrients to soils above agronomic rates does not pose an equivalent risk on water quality. Without hydrologic connectivity, for example, some soils may absorb high amounts of $\mathrm{P}$ without posing off-site water quality concerns. This water quality argument, however, is not equivalent to an endorsement for applying $\mathrm{P}$, a finite resource with limited low-cost deposit, to soil at high rates. Indeed, changing conditions can convert a hydrologically disconnected site into a hydrologically connected site. Such is the case with climate change, where higher frequency of extreme events may produce runoff from areas that, historically, were less hydrologically active. It is also the case with artificial drainage, such as the installation of standpipes and tile lines into potholes that were previously internally drained. Therefore, nutrient management must be seen in dynamic terms, always evolving.

While critical source area management or targeted conservation and 4R principles are key to sustainable nutrient management, there are times when strategies to mitigate water quality concerns related to nutrients, can conflict with other conservation efforts. Both no-till and cover crops are major areas of conservation investment and can be packaged together under various auspices, from soil conservation to nutrient recovery to soil health. Indeed, these practices are fully compatible with sustainable nutrient management and, in fact, contribute to nutrient conservation by reducing erosion, and even promoting greater rainfall infiltration in well-drained soils. However, it is well documented that no-till and cover crops can increase sources of soluble P near the soil surface, where they contribute to dissolved $\mathrm{P}$ in runoff, and can increase the potential leaching of $\mathrm{NO}_{3}^{-}$remaining in the soils profile after plant uptake. As a result, there are clear and well-reported trade-offs in conservation strategies that must first be acknowledged, even if they complicate local conservation messaging or other agendas. Fortunately, an array of practices can be applied to address phenomena, such as the vertical stratification of $\mathrm{P}$ in soils, although not all are palatable to dogmatic proponents of no-till.

\section{OUTCOMES}

Many examples now exist of local, state, regional, and even international efforts to improve water quality by curtailing agricultural nutrient losses. While successful outcomes can be achieved via a variety of approaches, effective mitigation programs tend to be those that embrace flexibility, promote adaptation as well as adoption, account for the production and management priorities in which they are being implemented, and leverage local sources of data to convince skeptical stakeholders. Uncertainty in the timing and extent of water quality response is an inherent component of mitigation programs and can be politicized to fit many agendas. Given the complexity of nutrient management and water quality challenges, comprehensive strategies that include local participation in their formulation tend to work best, even if they require greater resource investment, including time.

Ultimately, there is a need to rely upon evidence to gain acceptance. Monitoring remains the single most compelling form of information for convincing skeptics of the need for change (or lack thereof). However, monitoring introduces farmers, policy makers and the public to the role of uncertainty, brought about by spatial and temporal variability of weather and landscape controls. Empirical data alone, however, are insufficient. Process-based models are useful for connecting the dots between water quality data collected at different spatial scales, temporal scales, or climates. However, models can perpetuate error when the algorithms are incomplete or lack the science to support the complex processes occurring in natural systems.

In summary, nutrient management is a priority for agriculture, but nutrient management is not the priority for agriculture. No system is optimized around NUE and, while major opportunities exist to improve NUE in all production systems, they are only part of the solution to protecting water quality. Public expectation includes the message that farmers are doing many things to reduce nutrient losses and achieve gains in NUE, but there are still underperformers and there are areas in which either standard technologies have not advanced sufficiently for reasonable (market) adoption by most farmers, or there are factors far beyond the control of farmers that may delay water quality responses or undermine additional efforts. Some of these nutrient management concepts, complexities, inherent tradeoffs, and outcomes are summarized in table 1.

\section{REFERENCES}

Allred, B.J., D.L. Gamble, P.W. Levison, R.L. Scarbrough, L.C. Brown, and N.R. Fausey. 2014. Field test results for nitrogen removal by the constructed wetland component of an agricultural water recycling system. Applied Engineering in Agriculture 30(2):163-177.

Baker, J.L., K.L. Campbell, H.P. Johnson, and J.J. Hanway. 1975. Nitrate, phosphorus, and sulfate in subsurface drainage water. Journal of Environmental Quality 4:406-412.

Blann, K.L., J.L. Anderson, G.R. Sands, and B. Vondracek. 2009. Effects of agricultural drainage on aquatic ecosystems:A review. Critical Reviews in Environmental Science and Technology 39:909-1001.

Caires, E.F., R. Zardo Filho, G. Barth, and H.A.W. Joris. 2016. Optimizing nitrogen use efficiency for no-till corn production by improving root growth and capturing $\mathrm{NO}_{3}-\mathrm{N}$ in subsoil. Pedosphere 26:474.

Chen. G., Y. Chen, G. Zhao, W. Cheng, S. Guo. H. Zhang, and W. Shi. 2015. Do high nitrogen use efficiency rice cultivars reduce nitrogen losses from paddy fields? Agriculture, Ecosystems and Environment 209:26-33.

Christianson, L., A. Bhandari, M. Helmers, K. Kult, T. Sutphin, and R. Wolf. 2012. Performance evaluation of four field-scale agricultural drainage denitrification bioreactors in Iowa. Transactions of the American Society of Biological Engineers 55(6):2163-2174.

Christianson, L.E., J. Frankenberger, C. Hay, M.J. Helmers, and G. Sands. 2016. Ten ways to reduce nitrogen loads from drained cropland in the Midwest. Pub C1400. Urbana, IL: University of Illinois Extension.

Crumpton,W.G. 2001. Using wetlands for water quality improvement in agricultural watersheds: The importance of a watershed scale approach. Water Science and Technology 44(11-12):559-64. 
Crumpton, W.G., G.A. Stenback, B.A. Miller, and M.J. Helmers. 2006. Potential benefits of wetland filters for tile drainage systems: Impact on nitrate loads to Mississippi River subbasins. Final project report to U.S. Department of Agriculture, Financial Services Administration. Project number: IOW06682. https://www.fsa.usda.gov/Internet/FSA_File/ fsa_final_report_crumpton_rhd.pdf.

Daniels, M.B., A.N. Sharpley, R.D. Harmel, and K. Anderson. 2018. The utilization of edge-of-field monitoring of agricultural runoff in addressing nonpoint source pollution. Journal of Soil and Water Conservation 73(1):1-8, doi:10.2489/ jswc.73.1.1.

David, M.B., L.E. Gentry, D.A. Kovacic, and K.M. Smith. 1997. Nitrogen balance in and export from an agricultural watershed. Journal of Environmental Quality 26:1038-1048.

Dinnes, D.L., D.L. Karlan, D.B. Jaynes, T.C. Kaspar, J.L. Hatfield, T.S. Colvin, and C.A. Cambardella. 2002. Nitrogen management strategies to reduce nitrate leaching in tile-drained Midwestern soils. Agronomy Journal 94:153-171.

Dodd, R.J., and A.N. Sharpley. 2016. Conservation practice effectiveness and adoption: Unintended consequences and implications for sustainable phosphorus management. Nutrient Cycling in Agroecosystems 104:373-392.

Duan. Y., M. Xu, S. Gao. X. Yang, S. Huang, H. Liu, and B. Wang. 2014. Nitrogen use efficiency in a wheat-corn cropping system from 15 years of manure and fertilizer applications. Field Crops Research 157:47-56.

Duan. Y., Xu, B. Wang, S. X. Yang, S. Huang, and S. Gao. 2011. Long-term evaluation of manure application on maize yield and nitrogen use efficiency in China. Soil Science Society of America Journal 75:1562-1573.

Duncan, E.W., K.W. King, M.R. Williams, G. LaBarge, L.A. Pease, D.R. Smith, and N.R. Fausey. 2017. Linking soil phosphorus to dissolved phosphorus losses in the Midwest. Agricultural and Environmental Letters 2, doi:10.2134/ ael2017.02.0004. https://dl.sciencesocieties.org/ publications/ael/articles/2/1/170004?highlight $=\&$ search-result $=1$.

Fausey, N.R. 2003. Drainage: Inadequacy and crop response. In Encyclopedia of Water Science, eds. B.A. Stewart and T. Howell, 132-134. Oxford, UK: Taylor and Francis.

Fausey, N.R. 2005. Drainage management for humid regions. International Agricultural Engineering Journal 14:209-214.

Fixen, P., F. Brentrup, T. Bruulsema, F. Garcia, R. Norton, and S. Zingore. 2015. Nutrient/fertilizer use efficiency: Measurement, current situation and trends. In Managing Water and Fertilizer for Sustainable Agricultural Intensification, eds. P. Drechsel, P. Heffer, H. Magen, R. Mikkelsen, and D. Wichelns, 8-38. International Plant Nutrition Institute (IPNI), and International Potash Institute (IPI).

Fixen, P.E. 2007. Can we define a global framework within which fertilizer best management practices can be adapted to local conditions? IFA International Workshop on Fertilizer Best Management Practices (FBMPs), March 7-9, 2007, Brussels, Belgium, p. 77-86. Paris, France: International Fertilizer Industry Association (IFA).

Frankenberger, J.R., E. Kladivko, G. Sands, D. Jaynes, N. Fausey, M. Helmers, R. Cooke, J. Strock, K. Nelson, and L. Brown. 2007. Drainage water management for the Midwest. WQ-44. West Lafayette, IN: Purdue University Cooperative Extension Service.

Gaudin, A.C.M., K. Janovicek, B. Deen, and D.C Hooker. 2015. Wheat improves nitrogen use efficiency of maize and soybean-based cropping systems. Agriculture, Ecosystems and Environment 201:1-10.

Halvorson A.D., and M.E. Bartolo. 2014. Nitrogen source and rate effects on irrigated corn yields and nitrogen-use efficiency. Agronomy Journal 106:681-693.

Heppell, C.M., F.Worrall, T.P. Burt, and J.R.William. 2002. A classification of drainage and macropore flow in an agricultural catchment. Hydrological Processes 16:27-46.

Hudson, B.E. 1994. Soil organic matter and available water capacity. Journal of Soil and Water Conservation 49(2):189-194.

IDALS (Iowa Department of Agriculture and Land Stewardship), Iowa Department of Natural Resources, and Iowa State University College of Agriculture and Life Sciences. 2012. Iowa Nutrient Reduction Strategy: A science and technology-based framework to assess and reduce nutrients to Iowa waters and the Gulf of Mexico http://www.nutrientstrategy.iastate.edu/sites/ default/files/documents/NRSfull.pdf.

Jarvie, H.P., A.N. Sharpley, D. Flaten, P.J.A. Kleinman, A. Jenkins, and T. Simmons. 2015. The pivotal role of phosphorus in a resilient water-energy-food security nexus. Journal of Environmental Quality 44:1308-1326.

Jarvie, H.P., A.N. Sharpley, B. Spears, A.R. Buda, L. May, and P.J.A. Kleinman. 2013. Water quality remediation faces unprecedented challenges from "legacy phosphorus." Environmental Science and Technology 47:8997-8998.

Jaynes, D.B. 2015. Corn yield and nitrate loss in subsurface drainage affected by timing of anhydrous ammonia application. Soil Science Society of America Journal 79:1131-1141.

Jaynes, D.B., J.L. Hatfield, and D.W. Meek. 1999. Water quality in Walnut Creek Watershed: Herbicides and nitrate in surface waters. Journal of Environmental Quality 28:45-59.

Jaynes, D.B., and T.M. Isenhart. 2014. Reconnecting tile drainage to riparian buffer hydrology for enhanced nitrate removal. Journal of Environmental Quality 43:631-638.

Kaspar, T.C., D.B. Jaynes, T.B. Parkin, and T.B. Moorman. 2007. Rye cover crop and gamagrass strip effects on $\mathrm{NO}_{3}^{-}$concentration and load in tile drainage. Journal of Environmental Quality 36:1503-1511.

Kaspar, T.C., E.J. Kladivko, J.W. Singer, S. Morse, and D.R. Mutch. 2008. Potential and limitations of cover crops, living mulches, and perennials to reduce nutrient losses to water sources from agricultural fields in the Upper Mississippi River Basin. In Final Report: Gulf Hypoxia and Local Water Quality Concerns Workshop. St. Joseph, MI: American Society of Agricultural and Biological Engineers.

Kiani, M., M. Gheysari, B. Mostafazadeh-Fard, M.M. Majidi, K. Karchani, and G. Hoogenboom. 2016. Effect of the interaction of water and nitrogen on sunflower under drip irrigation in an arid environment. Agricultural Water Management 171:162.

King, K.W., N.R. Fausey, and M.R. Williams. 2014. Effect of subsurface drainage on streamflow in an agricultural headwater watershed. Journal of Hydrology 519:438-445.

King, K.W., M.R. Williams, G.A. LaBarge, J.M. Reutter, D.R. Smith, E.W. Duncan, and L.A. Pease. 2018. Addressing agricultural phosphorus loss in artificially drained landscapes with $4 \mathrm{R}$ nutrient management practices. Journal of Soil and Water Conservation 73(1):35-47, doi:10.2489/jswc.73.1.35.

King, K.W., M.R. Williams, M.L. Macrae, N.R. Fausey, J. Frankenberger, D.R. Smith, P.J.A. Kleinman, and L.C. Brown. 2015. Phosphorus transport in agricultural subsurface drainage: A review. Journal of Environmental Quality 44:467-485

Kladivko, E. J., J.R. Frankenberger, D.B. Jaynes, D.W. Meek, B.J. Jenkinson, and N.R. Fausey. 2004. Nitrate leaching to subsurface drains as affected by drain spacing and changes in crop production system. Journal of Environmental Quality 33:1803-1813.

Kleinman, P.J.A., A.N Sharpley, A. Buda, Z. Easton, J. Lory, D. Osmond, D. Radcliffe, N. Nelson, T. Veith, and D. Doody. 2017. The promise, practice and state of planning tools to assess site vulner- 
ability to runoff phosphorus loss. Journal of Environmental Quality 46:1243-1249.

Kornecki, T.S., and J.L. Fouss. 2001. Quantifying soil trafficability improvements provided by subsurface drainage for field crop operations in Louisiana. Applied Engineering in Agriculture 17:777-781.

Kovacic, D.A., M.B. David, L.E. Gentry, K.M. Starks, and R.A. Cooke. 2000. Effectiveness of constructed wetlands in reducing nitrogen and phosphorus export from agricultural tile drainage. Journal of Environmental Quality 29:1262-1274.

Kovacic, D.A., R.M. Twait, M.P. Wallace, and J. Bowling. 2006. Use of created wetlands to improve water quality in the Midwest-Lake Bloomington constructed wetlands case study. Ecological Engineering 28:258-270.

Lassaletta, L., G. Billen, B. Grizzetti, J. Anglade, and J. Garnier. 2014. 50 year trends in nitrogen use efficiency of world cropping systems: The relationship between yield and nitrogen input into cropland. Environmental Research Letters 9:105011.

Lawlor, P.A., M.J. Helmers, J.L. Baker, S.W. Melvin, and D.W. Lemke. 2008. Nitrogen application rate effect on nitrate-nitrogen concentration and loss in subsurface drainage for a corn-soybean rotation. Transactions of the ASABE 51:83-94.

Lehrsch, G.A., B. Brown, R.D. Lentz, J.L. JohnsonMaynard, and A.B. Leytem. 2016. Winter and growing season nitrogen mineralization from fall-applied composted or stockpiled solid dairy manure. Nutrient Cycling in Agroecosystems 104:125-142.

Magner, J.A., G.A. Payne, and L.J. Steffen. 2004. Drainage effects on stream nitrate-N and hydrology in south-central Minnesota (USA). Environmental Monitoring and Assessment 91:183-198.

Maguire, R.O., and J.T. Sims. 2002. Soil testing to predict phosphorus leaching. Journal of Environmental Quality 31:1601-1609.

Mahl, U. H., J.L. Tank, S.S. Roley, and R.T. Davis. 2015. Two-stage ditch floodplains enhance: N-removal capacity and reduce turbidity and dissolved $\mathrm{P}$ in agricultural streams. Journal of the American Water Resources Association 51:923-940.

Maltais-Landry, G., K. Scow, E. Brennen, E. Torbert, and P.Vitousek. 2016. Higher flexibility in input $\mathrm{N}: \mathrm{P}$ ratios results in more balanced phosphorus budgets in two long-term experimental agroecosystems. Agriculture, Ecosystems and Environment 223:197-210.

Marti, H.R., and H.A. Mills. 2002. Nitrogen and potassium nutrition affect yield, dry weight partitioning, and nutrient-use efficiency of sweet potato. Communications in Soil Science and Plant Analysis 33:287-301.

McIsaac G.F., M.B. David, and G.Z. Gertner. 2016. Illinois River nitrate-nitrogen concentrations and loads: Long-term variation and association with watershed nitrogen inputs. Journal of Environmental Quality 45:1268-1275.

Moll, R.H., E.J. Kamprath, and W.A. Jackson. 1982. Analysis and interpretation of factors which contribute to efficiency of nitrogen utilization. Agronomy Journal 74:562-564.
Mon, J., K.F. Bronson, D.J. Hunsaker, K.R. Thorp, J.W. White, and A.N. French. 2016. Interactive effects of nitrogen fertilization and irrigation on grain yield, canopy temperature, and nitrogen use efficiency in overhead sprinkler-irrigated durum wheat. Field Crops Research 191:54-65.

Osmond, D.L., D. Meals, D. Hoag, M. Arabi, A. Luloff, M. McFarland, G. Jennings, A.N. Sharpley, J. Spooner, and D. Line. 2012. Improving conservation practices programming to protect water quality in agricultural watersheds: Lessons learned from the National Institute of Food and Agriculture Conservation Effects Assessment Project. Journal of Soil and Water Conservation 67(5):122A-127A.

Pease, L.A., K.W. King, M.R. Williams, G.A. LaBarge, E.W. Duncan, and N.R. Fausey. 2018. Phosphorus export from artificially drained fields across the Eastern Corn Belt. Journal of Great Lake Research 44(1):43-53.

Penn, C.J., J.M. McGrath, E. Rounds, G. Fox, and D. Heeren. 2012. Trapping phosphorus in runoff with a phosphorus removal structure. Journal of Environmental Quality 41:672-679.

Pikul Jr., J.L. S.L. Osborne, and W.E. Riedell. 2012. Corn yield and nitrogen- and water- use under no-tillage rotations. Communications in Soil Science and Plant Analysis 43:2722-2734.

Powell, G.E., A.D. Ward, D.E. Mecklenburg, and W. Word. 2007. Two-stage channel systems: Part 2, case studies. Journal of Soil and Water Conservation 62(4):286-296.

Powell, J.M., T. Barros, M. Danes, M. Aguerre, M. Wattiaux, and K. Reed. 2017. Nitrogen use efficiencies to grow, feed, and recycle manure from the major diet components fed to dairy cows in the USA. Agriculture, Ecosystems and Environment 239:274-282.

Quemada M., M. Baranski, M.N.J. Nobel-de Lange, A.Vallejo, and J.M. Cooper. 2013. Meta-analysis of strategies to control nitrate leaching in irrigated agricultural systems and their effects on crop yield. Agriculture, Ecosystems and Environment 174:1-10.

Randall, G.W., D.R. Huggins, M.P. Russelle, D.J. Fuchs, W.W. Nelson, and J.L. Anderson. 1997. Nitrate losses through subsurface tile drainage in CRP, alfalfa, and row crop systems. Journal of Environmental Quality 26:1240-1247.

Reeve, J.R., J.L. Smith, L. Carpenter-Boggs, and J.P. Reganold. 2009. Glycine, nitrate, and ammonium uptake by classic and modern wheat varieties in a short-term microcosm study. Biology and Fertility of Soils 45:723-732.

Rens, L., L. Zotarelli, A. Alva, D. Rowland, G. Liu, and K. Morgan. 2016. Fertilizer nitrogen uptake efficiencies for potato as influenced by application timing. Nutrient Cycling in Agroecosystems 104:175-185.

Richardson, A.E., J.P. Lynch, P. R. Ryan, E. Delhaize, F.A. Smith, S.E. Smith, P.R. Harvey, M.H. Ryan, E.J. Veneklaas, H. Lambers, A. Oberson, R.A. Culvenor, and R.J. Simpson. 2011. Plant Soil 349:121-156.

Roberts, T.L. 2007. Right product, right rate, right time and right place... the foundation of best management practices for fertilizer. IFA International Workshop on Fertilizer Best Management Practices (FBMPs), March 7-9. 2007, Brussels,
Belgium, p. 29-32. Paris, France: International Fertilizer Industry Association (IFA).

Roley, S.S., J.L. Tank, M.L. Stephen, L.T. Johnson, J.J. Beulieu, and J.D. Witter. 2012. Floodplain restoration enhances denitrification and reach-scale nitrogen removal in an agricultural stream. Ecol. App. 22:281-297.

Ross, J.A., M.E. Herbert, S.P. Sowa, J.R. Frankenberger, K.W. King, S.F. Christopher, J.L. Tank, J.G. Arnold, M.J. White, and H. Yen. 2016. A synthesis and comparative evaluation of drainage water management. Agricultural Water Management 178:366-376.

Rowe,H.,P.J.A.Withers, P Baass, N.I. Chan, D. Doody, J. Holiman, B. Jacobs, H. Li, G.K. MacDonald, R. McDowell, A.N. Sharpley, J. Shen, W. Taheri, M. Wallenstein, and M.N. Weintraub. 2016. Integrating legacy soil phosphorus into sustainable nutrient management strategies for future food, bioenergy and water security. Nutrient Cycling in Agroecosystems 104:393-412.

Sands, G.R., I. Song, L.M. Busman, and B.J. Hansen. 2008. The effects of subsurface drainage depth and intensity on nitrate loads in the Northern Cornbelt.Transactions of the ASABE 51:937-946. Schlegel, A.J., and J.L. Havlin. 2017. Corn yield and grain nutrient uptake from 50 years of nitrogen and phosphorus fertilization. Agronomy Journal 109:335-342.

Schroeder, P.D., D.E. Radcliffe, and M.L. Cabrera. 2004. Rainfall timing and poultry litter application rate effects on phosphorus loss in surface runoff. Journal of Environmental Quality 33:2201-2209.

Serrano, S.E.H.R.W., and R.W. Irwin. 1985. Effects of agricultural drainage on streamflow in the Middle Thames River, Ontario, 19491980. Canadian Journal of Civil Engineering 12:875-885.

Shady, A.M. 1989. Irrigation, drainage, and flood control in Canada. Ottawa, ON, Canada: Canadian National Committee on Irrigation and Drainage.

Sharpley, A.N., L. Bergström, H. Aronsson, M. Bechmann, C. Bolster, K. Börling, F. Djodjic, H. Jarvie, O. Schoumans, C. Stamm, K. Tonderski, B. Ulen, R. Uusitalo, and P. Withers. 2015. Future agriculture with minimized phosphorus losses to waters: research needs and direction. AMBIO 44(suppl 2):S163-S179.

Sharpley, A.N., R.W. McDowell, and P.J.A. Kleinman. 2001. Phosphorus loss from land to water: integrating agricultural and environmental management. Plant Soil 237:287-307.

Sims, J.T., R.R. Simard, and B.C. Joern. 1998. Phosphorus loss in agricultural drainage: Historical perspective and current research. Journal of Environmental Quality 27:277-293.

Siyal, A.A., K.L. Bristow, and J. Simunek. 2012. Minimizing nitrogen leaching from furrow irrigation through novel fertilizer placement and soil surface management strategies. Agricultural Water Management 115:242-251.

Skaggs, R.W., M.A. Breve, and J.W. Gilliam. 1994. Hydrologic and water quality impacts of agricultural drainage. Critical Reviews in Environmental Science and Technology 24:1-32.

Skaggs, R.W., and R.G. Broadhead. 1982. Drainage Strategies and Peak Flood Flows. St. Joseph, MI: American Society of Agricultural Engineers. 
Smith, D.R., R.D. Harmel, M. Williams, R. Haney, and K.W. King. 2016. Managing acute phosphorus loss with fertilizer source and placement: Proof of concept.Agricultural and Environmental Letters 1, doi:10.2134/ael2015.12.0015.

Smith, D.R., and C. Huang. 2010. Assessing nutrient transport following dredging of agricultural drainage ditches. Transactions of the ASABE 53:429-436.

Smith, D.R., K.W. King, L. Johnson, W. Francesconi, P. Richards, D. Baker, and A.N. Sharpley. 2015. Surface runoff and tile drainage transport of phosphorus in the Midwestern United States. Journal of Environmental Quality 44:495-502.

Smith, D.R., and S.J. Livingston. 2013. Managing farmed closed depressional areas using blind inlets to minimize phosphorus and nitrogen losses. Soil Use and Management 29:94-102.

Smith, D.R., P.R. Owens, A.B. Leytem, and E.A Warnemuende. 2007. Nutrient losses from manure and fertilizer applications as impacted by time to first runoff event. Environmental Pollution 147:131-137.

Spaling, H., and B. Smit. 1995. Conceptual model of cumulative environmental effects of agricultural land drainage. Agriculture, Ecosystems, and Environment 53:299-308.

Stoner, D., C. Penn, J. McGrath, and J. Warren. 2012. Phosphorus removal with by-products in a flow-through setting. Journal of Environmental Quality 41:654-663.

Sugg, Z. 2007. Assessing U.S. Farm Drainage: Can GIS lead to better estimates of subsurface drainage extent? Washington, DC: World Resources Institute Bulletin.

Syers, J.K., A.E. Johnston, and D. Curtin. 2008. Efficiency of soil and fertilizer phosphorus use Reconciling changing concepts of soil phosphorus behavior with agronomic information. FAO Fertilizer and Plant Nutrition Bulletin 18. Rome: Food and Agriculture Organization of the United Nations.

Tomer, M.D., D.W. Meek, and L.A. Kramer. 2005. Agricultural practices influence flow regimes of headwater streams in western Iowa. Journal of Environmental Quality 34:1547-1558.

Tonitto, C., M.B. David, and L.E. Drinkwater. 2006. Replacing bare fallows with cover crops in fertilizer intensive cropping systems:A meta-analysis of crop yield and $\mathrm{N}$ dynamics. Agriculture, Ecosystems and Environment 112:58-72.

Williams, M.R., K.W. King, W.I. Ford, A.R. Buda, and C.D. Kennedy. 2016. Effect of tillage on macropore flow and phosphorus transport to tile drains. Water Resources Research 52:2868-2882.

Williams, M.R., K. W. King, L.T. Johnson, D.R. Baker, D.R. Smith, and N.R. Fausey. 2015. Hydrologic and biogeochemical controls on phosphorus export from Western Lake Erie tributaries. International Journal of Great Lakes Research 42:1403-1411.

Wiskow, E., and R.R.van der Ploeg. 2003. Calculation of drain spacing for optimal rainstorm flood control. Journal of Hydrology 272:163-174.

Withers, P.J.A., R. Sylvester-Bradley, D.L. Jones, J.R. Healey, and P. J. Talboys. 2014. Feed the crop not the soil: Rethinking phosphorus management in the food chain. Environmental Science and Technology 48:6523-6530.

Woli, K.P., M.J. Boyer, R.W. Elmore, J.E. Sawyer, L.J. Abendroth, and D.W. Barker. 2016. Corn era hybrid response to nitrogen fertilization. Agronomy Journal 108:473-486.

Yang, Y., M. Zhang, Y.C. Li, X. Fan, and Y. Geng. 2012. Controlled release urea improved nitrogen use efficiency, activities of leaf enzyme and rice yield. Soil Science Society of America Journal 76:2307-2317.

Zotarelli, L., L.R. Rens, D.J. Cantliffe, P.J. Stoffella, D. Gergela, and D. Burhans. 2015. Rate and timing of nitrogen fertilizer application on potato 'FL1867'. Part I: Plant nitrogen uptake and soil nitrogen availability. Field Crops Research 183:246-256.

Zucker, L.A., and L.C. Brown. 1998. Agricultural drainage: Water quality impacts and subsurface drainage studies in the Midwest. St. Paul, MN University of Minnesota Extension. 